\title{
Reputation, inequality and meeting techniques: visualising user hierarchy to support collaboration
}

\author{
Karin Hansson • Petter Karlström • Aron Larsson • \\ Harko Verhagen
}

Published online: 5 September 2013

(C) Springer Science+Business Media New York 2013

\begin{abstract}
Equality within groups is ordinarily taken for granted when technology for e-democracy is conceived and developed. However, inequality in online communication is just as common as in other social contexts. Therefore, we have developed a groupware with the express purpose of illuminating imbalance of power. Inequalities are measured and made visible to users of the system, and they change dynamically as actions are taken by users. The system is based on democratic meeting techniques and is reminiscent of a strategy game based on social media. Each participant's score within the game is dynamically calculated and reflects that user's activity, others' reactions to that activity and reactions to others' activities. The calculations and weighing mechanisms are open to inspection and change by the users, and hierarchical roles reflecting game levels may be attached to system rights belonging to individual users and user groups. The prototype we present stems from the question of how to conceive of groupware based on diversity and is the result of combining social theory with algorithms for modelling and visualising user hierarchy and status. Empirical user tests suggest improvements to the prototype's interface, which will be implemented and further evaluated by embedding the algorithms in a system for eparticipation.
\end{abstract}

Keywords E-Participation · Reputation · Inequality · Collaboration

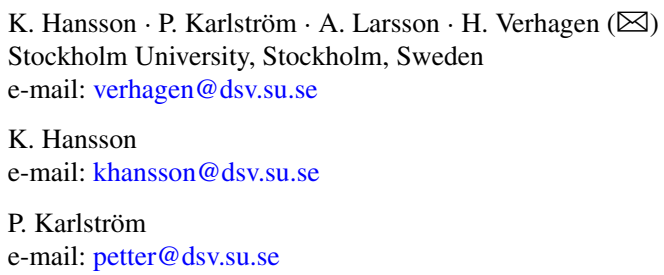

A. Larsson

e-mail: aron@dsv.su.se 


\section{Introduction}

In the early discourse on the Internet and e-democracy, the absence of the body and its attributes suggested the Internet to be a neutral place where different people could come together and develop a deliberative democratic discourse (Herring 2000; Witschge 2002). In this ideal speech situation participants would reach consensus on rational grounds and technology would diminish differences between people, regarding body, time and space. This view of the Internet as a neutral medium that fosters consensus still characterises many of the contemporary attempts to use it as a forum where participants from different groups, officials and politicians can meet (Dahlberg 2007; Hands 2005; Macintosh et al. 2009; Witschge 2002).

Gender research concerning new media argues that social media such as chat rooms, online games, etc. are far from neutral places where participants are treated equally but instead are places where gender, race, ethnicity and other grounds of discrimination are just as prominent as in other social contexts and that hierarchies and status are reproduced online (Herring 2008; Kampen and Snijkers 2003; Nakamura 2001; Postmes and Spears 2002; Wright 2005). In practise, communication technology may reinforce differences between individuals and groups in society rather than bringing diverse groups and perspectives together (Dutta-Bergman 2005; Norris 2001).

In the fields of political science and political philosophy, the Habermasian idea of a deliberative democracy has been widely discussed and developed (e.g. Dahlberg 2007; Dryzek 2005; Fraser 1985; Mouffe 1999). However, in technological development in the area of e-democracy a more nuanced understanding regarding the importance of form and structure in democracy is seldom articulated (Macintosh et al. 2009; Sæbø et al. 2008). Instead, what is mostly emphasised is the ability to create a neutral place for deliberative discussions, where the view is that technology can enable a stronger democracy (Dahlberg 2011). Even from a more radical democratic perspective, where difference on a societal level is emphasised and the importance of separatist counter-publics is put forward, in-group equality is taken for granted. Despite the rapid growth of social networks, which indicates that the political discussion takes place elsewhere than on governmental web sites, efficient technology design to support representation and analysis of representation is lacking (Macintosh et al. 2009).

In an exhaustive review of current research on e-participation, Sæbø et al. (2008) discuss a technological agenda for the field. The paper states that most software products are adaptations of existing technologies without much technological innovation, that the internet is treated as a distinct artifact, and that technological solutions are mostly taken for granted (with the exception of systems for e-voting).

It seems that there is a gap between theory-driven research, where technology most often is seen as given, and technology-driven research, where theory is seen as given. We intend to bridge this gap by not treating technology as a neutral means to an end. Instead, we treat it as cultural production where norms and social practises are expressed in the system design. As a starting point, we challenge the presumption that members of an interest group are equals. Instead of developing a system based on an ideal speech situation, we suggest a system based on the opposite, a technological 
tool that takes differences between people into account and even makes it the pointof-departure. The research questions in this paper are: How should a system based on diversity be conceived? and How is it possible to visualise and communicate power structures in the system's design without emphasising or simplifying them?

By diversity we mean not only varieties and differences between people but the notion that all variety between people also implies inequality. In other words, there are adverse as well as positive effects of diversity, and an urgent question is how to strengthen the positive ones and alleviate the negative ones. One possible way of reducing negative aspects is by communicating power structures to all participants, bringing power relations and hierarchy out for inspection, reflection, and discussion. However, merely displaying power structures might reinforce them rather than alleviate them. Therefore, some care must be taken in the aim of designing a system promoting diversity yet demoting fossilisation of inequalities. This calls for dynamic ways of representing participants' status and hierarchy in the system that are grounded in social theory. In order to find guidelines for the design of such a system, we have grounded our designs in democratic meeting techniques and feminist and discursive social theory. These positions in social theory and their implications for design will be elaborated on in the following two sections. Formalisation of the political and theoretical positions into a mathematical model follows, as well as a preliminary evaluation and discussion of the system's consequences. The resulting system is called "Actory", its name emphasising actions and reactions of participants and that it is activity that influences their relative hierarchy and status.

\section{Democratic meeting techniques}

Following Dahl (1989), Hemberg (2002) created a model of democracy that is useful as a way of measuring participation on different levels, from countries and organisations to smaller interest groups. Five criteria are stated for fulfilling the ideal democratic situation:

1. Participants are equal members

2. Participants set the agenda together

3. Participants can fully participate in the discussion

4. All participants have the same status when decisions are taken

5. Everyone has an enlightened understanding of the discussion

These criteria can be used to analyse any situation from a participatory perspective in order to find methods to improve democracy in the actual situation. Democratic meeting techniques are not a fixed set of methods but a way of maintaining a reflexive process.

Democratic meeting techniques as developed in critical pedagogy and in feministoriented movements can be seen as an elaboration of established meeting techniques (i.e. setting an agenda, having rules for turn-taking and speaking, and having procedures for voting). While these traditional techniques assume that all participants are relatively equal, the elaborated techniques emphasise that people do not participate on equal conditions, that they have different capacities to participate, and that they are 
treated differently depending on interacting power structures. The underlying idea is that status and power are created in relation to others without being assigned a fixed category such as "man" or "black". Power is created in the intersection of multiple categories.

One method to increase participants' awareness of the importance of power structures is to observe the conditions for dialogue in the meeting situation, e.g. who gets the most space and attention, who is ignored, and how suppression techniques are used (Hedenstrand 2008; Hemberg 2002). Different communication forms produce different results, and people are more or less at ease when expressing themselves, depending on the situation. In a critical and feminist pedagogic perspective, the importance of diverse forms of communication that take peoples' different capabilities and experiences into account is therefore emphasised (Bondestam 2002; Enns and Sinacore 2005; Howie and Tauchert 2001; Maher and Thompson Tetreault 2001). An informal discussion can be seen as a complex value system where participants control the stage by, for example, encouraging or ignoring some people and going into heated argumentation with others. There are several meeting techniques that emphasise complexity and offer diverse possibilities for debate to encourage different kinds of participation styles. Open space technology is one example where written comments as well as informal oral discussions are used to put together an agenda (Owen 1997). The ambition is to create the agenda together and prepare it in self-organised groups in an organic but efficient process before any decisions are taken.

\subsection{Technology and discursive democracy}

There are several examples of digitally mediated self-organised systems that contain functionality similar to those used in democratic meeting techniques. Wikis are a concept where many of the aspirations of deliberate democracy are fulfilled (Klemp and Forcehimes 2010). Referring to the work of Dryzek (2005) on deliberative democracy, Lourenço and Costa (2010) define blogs and wikis as "discursive forums". These are places where peers can develop a common discourse around shared interests, and these discourses can, in the long run, influence democratic decision-making.

Dahlberg (2011) suggests that democracy in self-organised systems such as social media is to be understood as an autonomous system that goes beyond the centralised power of the nation-state, and where the network is the organisational principle. In this so-called open source production, decision-making takes place in the collaborative, decentralised network of peers. Communication forms associated with social media and Web 2.0 are examples where technology supports this kind of e-democracy through a mix of different discussion forms, motivating and voting systems and possibilities to extend communication in different ways; linking, liking, blogging, digging, tweeting. Here, value systems are created using reputation to validate content rather than using the legitimacy of conventional institutional frameworks. Instead, quality is measured by the crowd of users, as, for example, in auction services such as Ebay, where customers validate the trustworthiness of the seller. Garcin et al. (2009) show how important the particular algorithms and calculations are when the micro feedback of the crowd is aggregated. Despite this, the algorithms involved are never completely visible or open to changes by users. 


\subsection{Reputation in social simulation}

In social simulations studies, a few different frameworks for modelling reputation have been proposed (Hahn et al. 2007; Sabater et al. 2006; Muller and Vercouter 2010). However, all three of these models are based on economic interactions (or modelled as such), where the evaluation of reputation is used to decide whether to sell/buy to/from another agent or not. In our case, reputation reflects communicative interaction rather than economic interaction, interaction between one agent and many other agents simultaneously, and an evaluation that is cognitive rather than economic. One similarity with other models is the need to model both direct and indirect interactions. In our case, direct interactions are of various kinds (represented by different feedback mechanisms) whereas the indirect interaction is managed in the reputation calculation system (Actory).

A dissimilarity is that in the three models, knowledge of reputation is distributed in the agent population, in contrast to the reputation system in, for example, Ebay which like our system has a centralised reputation value. We are aware that the one centralised value model misses out on some of the more subtle sides of reputation; however in the situation in which it is used in our system we believe these subtleties to be represented well enough by the openness of the system and the diversity of the actions weighed into the reputation measure, enabling the users to define how the calculations will be performed.

\subsection{Game challenge to influence behaviour}

One can view the use of reputation in social media as an economic system for social capital, or a strategy game. Most games contain an economy of some sort where the challenge is to accumulate resources, where the users often gain levels and earn "scores" by doing different activities (Adams and Rollings 2007). Some social media also use this game aspect in order to motivate the use of the system and to foster certain behaviour. For example, LinkedIn (http://www.linkedin.com) encourages users to add information to the system in order to gain "profile completeness", which means submitting different kinds of information and adding a certain number of contacts. Swedish Lunarstorm (http://en.wikipedia.org/wiki/LunarStorm) was another social networking website that used an economic challenge to make people explore and use all parts of the system. In this system, active users received attention and sometimes rewards for their participation. A more recent example of the use of reputation as a direct way to get rewards is Klout (klout.com). In Klout, the user online "influence" is measured and rewarded with special product offers. The Klout score (on a scale 1-100) is also visible to other users. A final example is the widely used Disqus (http://disqus.com) system, which in 2011 released a service that closely resembles our system in that it uses multiple feedback mechanisms. However, the functionality of this system is only partly revealed and thus far from transparent. This holds for all social media applications we have analysed. 


\section{System design}

Dahlberg (2011) suggests that an important part of e-democracy takes place outside of the development of government initiated e-democracy projects. Instead, it occurs in collaborative decentralised interest-based networks. In order to create a system that supports and conceptualises more autonomous decentralised parts of e-democracy, we have instrumentalised some of the norms and practises that were synthesised from democratic meeting techniques and social media discussed in the previous section. Our ambition here is to create:

1. A discursive forum: The software should support development of common questions, rather than decision-making. Anyone should be able to propose an activity and implement it without the need for formal voting and discussion.

2. Ubiquitous voting: Informal voting should be on-going and everywhere.

3. Measuring activity: A person's score in the system should be created through her and others' actions. Everyone's status in the system should be taken into account when judging action.

4. Visualised reputation: An informal hierarchy should be visualised.

5. Challenging game: Gaining score should be challenging in order to motivate and encourage participation.

We elaborate on each of these points in the following Sects. 3.1-3.5, where we describe how these norms and practises are expressed in the system design.

\subsection{Discursive forum}

Our intention is not to develop a formal voting system but a platform that supports development of common discourses-like the development of a political agenda or a collaborative cultural production. Therefore we build on the principles of a wiki, a platform that suits discursive processes. A wiki gives the user an opportunity to develop information in collaboration with other users in a simple way. One important criterion of democracy, according to Hemberg (2002), is to be able to set the agenda. In a wiki, the opportunity for anyone to raise a question and create a space for the discussion around it is technically unlimited.

In a more informal grouping, the subjective experience is important and it is the individual who decides what is relevant for her to discuss and how it relates to the overall theme. Therefore we have added the feature that the user who creates a post also controls this micro-forum and decides if she wants to invite others to the writing process or just as commenters. In order to make the information structure simple to use and to facilitate the development of a common discourse, we use association as a way of structuring instead of categorising. A requirement to link a post to an earlier post forces the user to refer to at least one source within the system and this contributes to an emphasis on the development of a common discussion.

\subsection{Ubiquitous voting}

In a collaborative, decentralised network of peers, there are constant negotiations about what to do and cooperation is not steered by a centralised formal voting process. Democratic meeting techniques acknowledge that the arrangements for voting 
are important for participation and outcome and therefore seek to vary forms of discussion and voting (Hemberg 2002). Our proposed system emphasises different kinds of activities and gives scores not only for direct voting but for all kinds of attention: linking, commenting, clicking a like/dislike button, and rating. These different possibilities to express meaning as a numeric value can be unrestricted or restricted in time and quantity. In the scoring process, both users and their actions are given scores, creating a hierarchy not only between users but also between posts.

A "like" option that is easy to click on is commonplace in social media in order to provide users with a possibility to quickly express their opinion. This is often combined with a rating system that demands slightly more reflection. Some blogs provide users with a set of tools to evaluate and disseminate information widely through services such as Digg and Twitter. Our idea is to reconnect the value of this kind of informal voting directly to the user and also to create an understanding of the valuation process. The valuation is bi-directional; the reference is a way to legitimise the own statement and also a way to legitimise other people who use the same reference. When linking to someone's post, it adds score both to the user and the post. The amount of score can also depend on the actory index of the user, which is the user's percentage of the total amount of score in the system multiplied by the total number of users.

\subsection{Measuring activity}

Visualising communication structures may make the represented structure more permanent. An important question then is how to make structures visible without entrenching hierarchies. Another question is how status should be estimated. A situation where everyone rates one another in a constantly on-going voting process is not only time-consuming, it can be difficult to get people to want to participate. Our solution to these two questions is to focus less on actors and more on actions. Following a critical and feminist pedagogic perspective, we assume participants will give more attention to people with high status and to people in their network. Reputation most often refers to an opinion that an agent has of another agent's intentions and norms. We emphasise that this opinion is influenced by socially structuring factors: people who have a high status may get more attention and their actions may be valued more highly by other users. Beginners and other people can instead compensate for their low status by being more active. The system may thus work in an emancipatory way. By visualising reputation as a way of formalising informal social processes, we will be able to use the system for understanding structural mechanisms empirically in unequal settings.

\subsection{Visualised status}

If we assume that groups are always structured and therefore that the power distribution within the group is more or less unequal, a transparency of the structures can clarify user strategies and system rules in an empowering way. We start with the premise that users receive recognition through the way they use the tool, and that others' reactions also depend on the status they attribute to the user due to structuring factors such as gender, class, and ethnicity. 


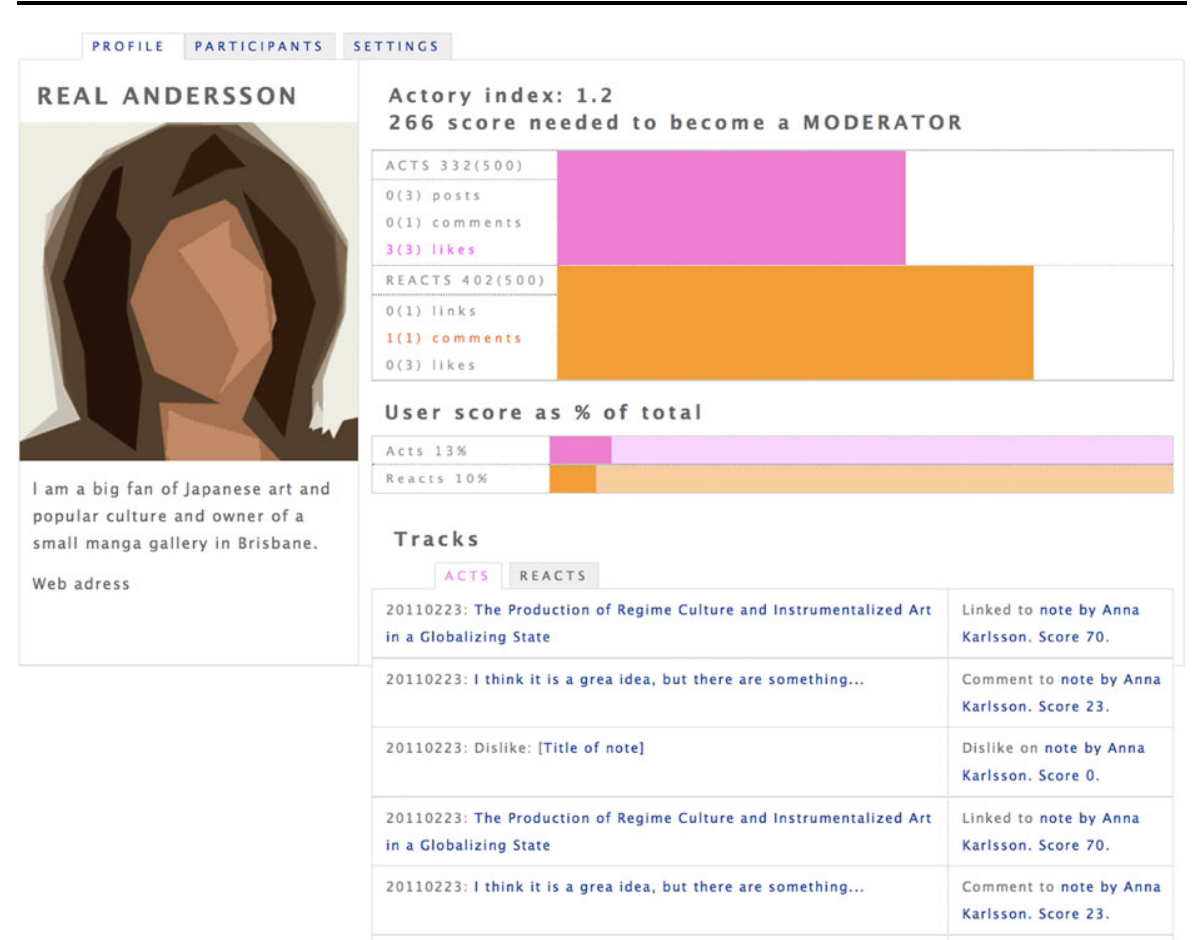

Fig. 1 Web-based prototype built in Drupal visualising user state

The system consists of three different parts: Activity, About and State. Activity is where new activities are suggested and debated inside a group and are partly displayed on the public web as a news feature. About is where the result of the collaborative work is manifested outwards and where the overall topic that functions as the starting point for the work is expressed. State is where the individual score is visualised and roles and score levels are set (Fig. 1). Of these three parts, State stands in focus here. Participants' State is measured in two ways: through the activities users initiate and by the reactions from others to these activities. User score level thus depends on the score of the activity the individual creates in the system (Acts) and the score others give the individual actions in the system (Reacts). Depending on the purpose of the system, the setting of the score can be changed, emphasising either Acts or Reacts.

\subsection{Challenging game}

In order to motivate and encourage participation, the system has to be challenging and rewarding. One can see the system as a strategic game, where increasing one's influence is a goal in itself. Most games contain an economy of some sort where the challenge is to accumulate resources. Users often level up and earn "score" by conducting different activities (Adams and Rollings 2007). The game aspect of the system can create an incentive to participate, even when the participant does not have 
an enlightened understanding of the "game". A certain hierarchy can be used as a means to develop a certain type of behaviour and communicate the functionality of the interface but also to create stability and to motivate people with high status (which we assume is due to knowledge and experience) to continue to participate. Users' score levels can have a direct function, giving a user that has gained a high score greater influence over the formulation of the collective goal. System roles could also be set dynamically, giving the user more and more influence over the system, apart from being set by an administrator.

\subsection{Summary of design principles}

The system can be summarised in five design principles as follows:

1. A discussion forum, like a wiki, that supports open source cultural production. Users have the right to edit their own posts and to delegate this right. Association structures the information.

2. Informal voting is done constantly and in different fashions: linking, commenting, liking/disliking, and rating.

3. The scores that are generated by users' activities depend on each user's total score level. A user's total score depends on their own activity and the score that others give that user's activity. The percentage of scores for users and posts is dynamic and depends on the total distribution of points among users and posts.

4. Transparency and visualisation clarify user strategies, system rules, roles, and rights.

5. Hierarchy can be used as a way of communicating the system and motivating participation.

The system can be described as a wiki combined with an evaluation system that tracks all activities of the users including the reactions of other users in relation to a specific action. Any comment, like/dislike, or link action creates a score. Each new score affects other users' scores in all parts of the system, as each user's actory index is calculated in relation to the total amount of score in the system. Furthermore, how many points are given (by making comments, links, like/dislike, grades) depends on who reacted. As the user's actory index is constantly changing, and as some old posts might be updated with new links and comments, the order of the archive is dynamic as each post depends on changes in the total system (Fig. 2).

\section{Implementation}

\subsection{The scoring system}

Part of how the distribution of scores between users when they post or comment is illustrated in Fig. 3. A distinguishing mark of the proposed system is that scoring is multi-directional. For example, when commenting on a post the commenting user receives score, as this user demonstrates activity, as does the owner of the post and the post itself because these entities are subject to attention. Another example is that when writing a new post and linking to another post, both post owners receive score. 


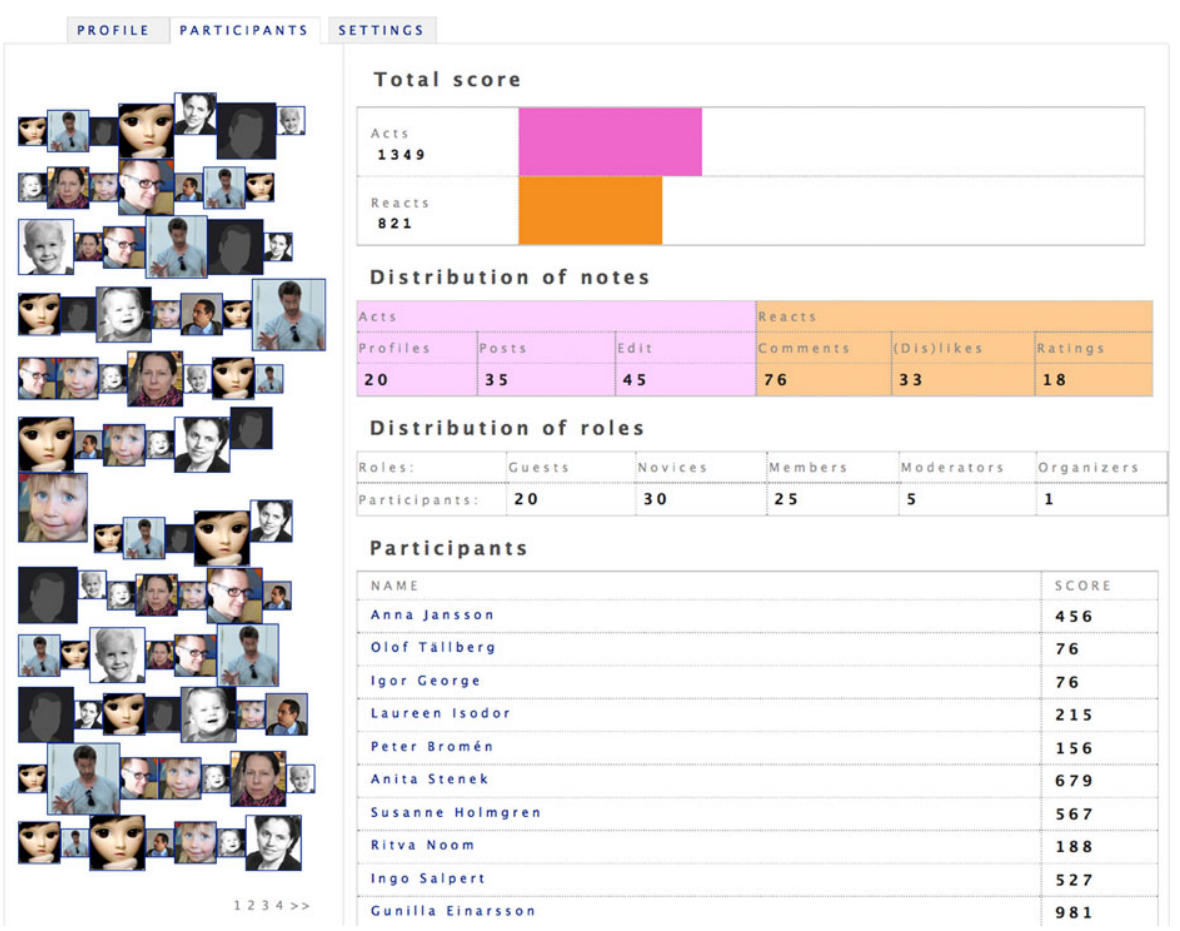

Fig. 2 Web-based prototype built in Drupal visualising distribution of total score and roles of users

We now outline how scores are calculated in the event of an action. Let an action $x$ be initiated by user $u_{i}$. We now use two pre-defined mappings relative to the current system, the default score function $s(x)$ and the status impact function $t(x)$. See Fig. 6 columns "Score" and "Status impact" for an example of $s$ and $t$, respectively. The default score function simply represents the minimum score that an action generates, while the status impact function yields a multiplicative factor. We then define the status impact function for action $x$ and user $u_{i}, t_{i}(x, j)$ as

$$
t_{i}(x, j)= \begin{cases}t(x) & \text { if } i \neq j \\ 0 & \text { if } i=j\end{cases}
$$

In words, the status impact function for user $u_{i}$ equals zero if $x$ was initiated by $u_{i}$, otherwise it equals $t(x)$. The score $r$ awarded to user $u_{i}$ for the action $x$ initiated by any user $u_{j}$ is obtained from the following equation:

$$
r(x, j)=s(x)\left[1+t_{i}(x, j) \cdot a_{j}\right]
$$

where $a_{j}$ is the actory index for user $u_{j}$. This is defined in Sect. 4.2.

In Fig. 3, user B comments upon a post by user A. B receives a score of $r(x, j)=$ 20 for the comment, as $r(x, j)=s(x)$. A and the post that is commented on also receive score for the comments from B. A receives a score of $r(x, j)=20(1+2 \times$ $1,5)=80$. In Fig. 4, user C creates a post that links to a post by user A. This generates scores for the post plus for user $\mathrm{C}$ and also for user $\mathrm{A}$ and the post that gets linked to. As user $\mathrm{C}$ has a low actory index, the generated score is rather low. 


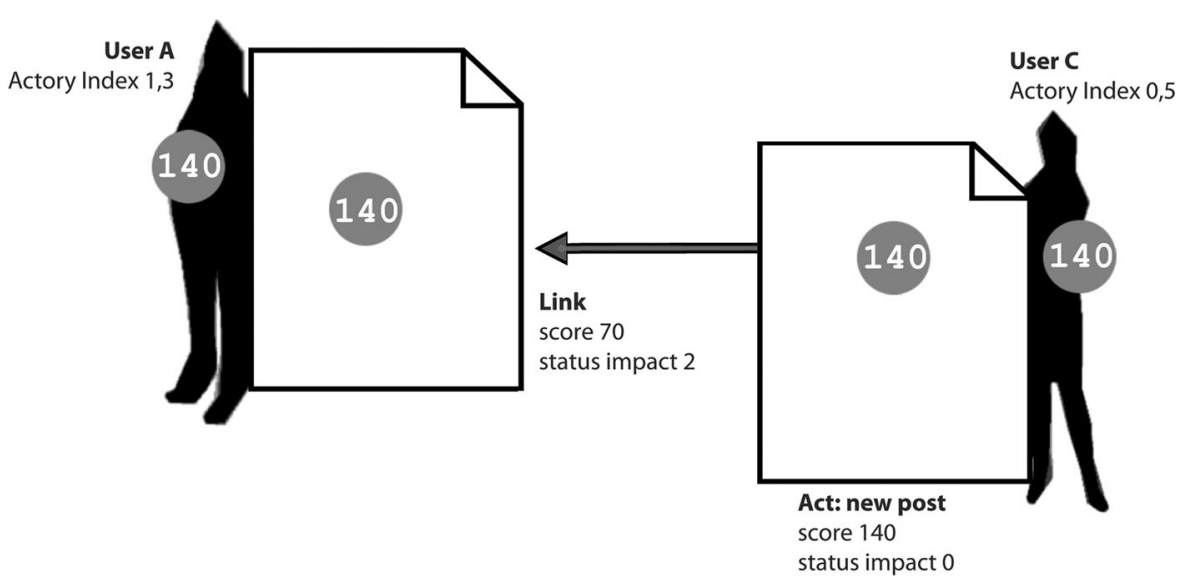

Fig. 3 The distribution of score between users and activities when a user creates a post

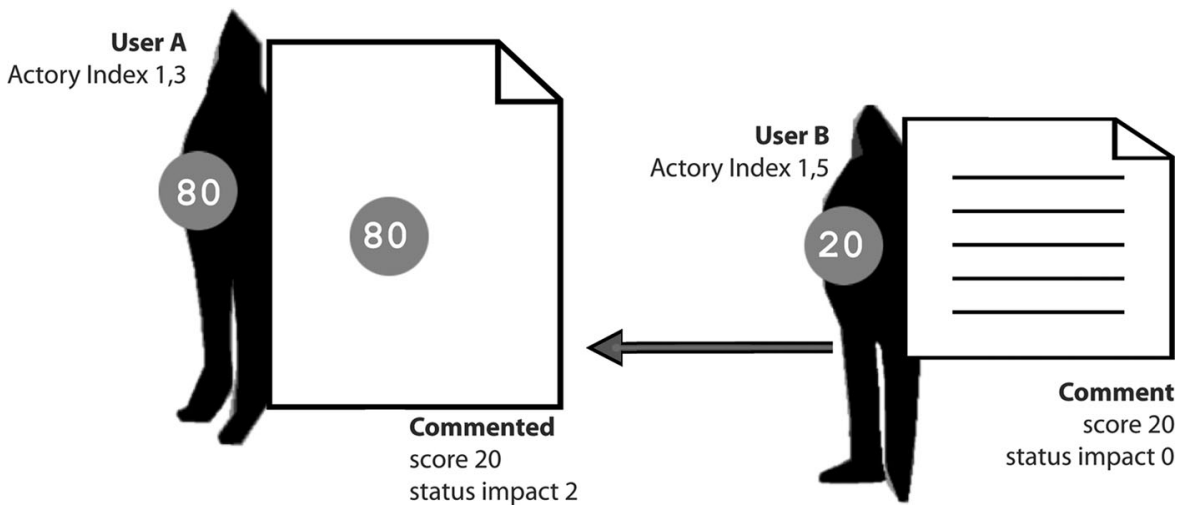

Fig. 4 The distribution of score between users and activities when a user comments on a post

\subsection{The actory index}

The intention is not only to visualise the users' relative status in the system, but also to use this information to enhance hierarchy. We devised an actory index that is used to generate scores which are dependent on users' statuses within the system. For any instance of the system we have a finite set of users $U=\left\{u_{1}, u_{2}, \ldots, u_{N}\right\}$, where each user $u_{i}$ is associated with a score level $s_{i}$, i.e. the amount of score they have achieved from actions or reactions. The actory index $a_{i}$ for a user $u_{i}$ is defined as $u_{i}$ 's percentage of the total score in the system multiplied by the number of users, such that

$$
a_{i}=N \frac{s_{i}}{\sum_{u_{j} \in U} s_{j}}
$$




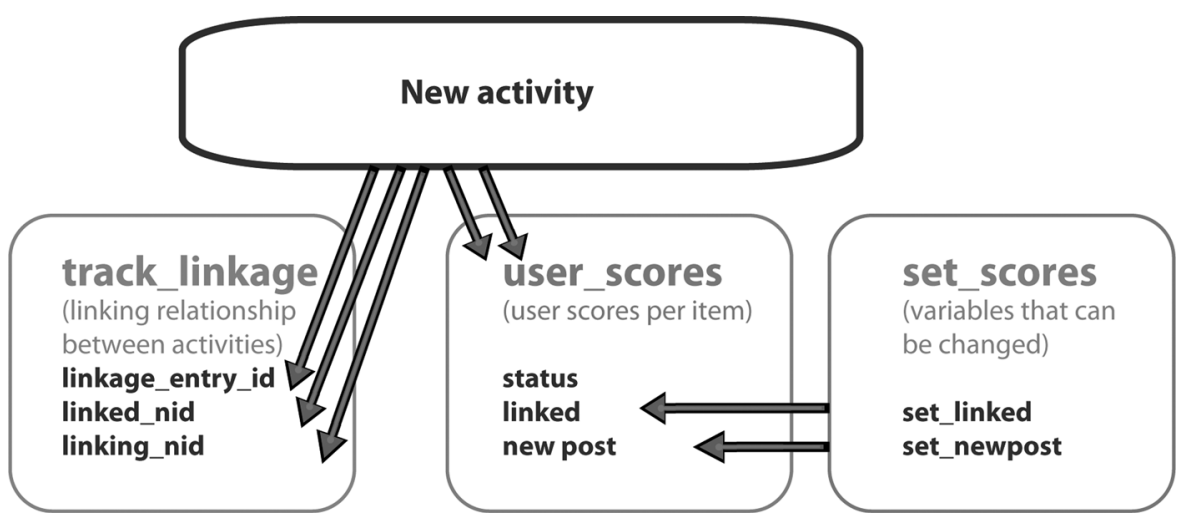

Fig. 5 The scoring system in Drupal when creating an activity

In this manner the actory index has an upper bound of $N$, the number of users. This enables a visualisation of greater inequalities between users in systems with many users than in systems having just a few users.

This suggested logic was implemented and tested in a spreadsheet using a scenario with three fictional users involved in a dialogue that consisted of 28 activities. Figure 5 illustrates the implementation of the scoring system in our Drupal prototype. The table track_linkage stores the linked and the linking activity. The user who created the linked activity receives a linked score in the user_scores table. The user who is linking the activity receives a new post score in the user_scores table. The set_score table stores variables that can be set and changed by the user/organiser.

\subsection{Designing the rules of the social game}

Informal voting is ubiquitous and performed in different ways: linking, commenting, liking/disliking, and rating. We have chosen to use these features for the sake of simplicity. They are common in social media and are simple to understand and use for most users. The score given for each feature depends on the social context and what kind of discussion one would like to promote. Different behaviours may then be stimulated and rewarded by redefining the score and the use of the actory index. What emphasis is put on each feature thus creates the informal rules of the collaboration. The rules can be set and changed by the organiser but can also be set by the users. What each user can do depends on how the system is configured from the start. Permission to change the score and the importance of status impact can be open to the administrator only, to a few users depending on their status in the system, or to all users.

We exemplify our system with two templates reflecting different goals with respect to the type of activity aimed for in the discussions. In Figs. 6 and 7, the values that are coloured in red are open for change to users with the status "organiser", and the grey areas indicate different permissions due to user status. In the template "Initiative" in Fig. 6, the value of adding a new post is relatively high in order to promote new initiatives. Features such as like/dislike provide an easy way of expressing an opinion 


\begin{tabular}{|c|c|c|c|c|c|c|c|c|}
\hline & & \multicolumn{2}{|c|}{ Variables } & \multicolumn{5}{|l|}{ Roles } \\
\hline \multicolumn{2}{|l|}{ Rights } & Score & $\begin{array}{l}\text { Status } \\
\text { impact }\end{array}$ & Guest & Novice & Member & Moderator & organizer \\
\hline \multirow{9}{*}{ Acts } & $\begin{array}{l}\text { new } \\
\text { post }\end{array}$ & 140 & $\times 0$ & $\times 0$ & $\times 0$ & $\times 0$ & $\times 0$ & $\times 0$ \\
\hline & edit & 10 & $\times 0$ & $\times 0$ & $\times 0$ & $\times 0$ & $\times 0$ & $\times 0$ \\
\hline & comment & 20 & $\times 0$ & $\times 0$ & $\times 0$ & $\times 0$ & $\times 0$ & $\times 0$ \\
\hline & like & 10 & $\times 0$ & $\times 0$ & $\times 0$ & $\times 0$ & $\times 0$ & $\times 0$ \\
\hline & dislike & 0 & $\times 0$ & 0 & $\times 0$ & $\times 0$ & $\times 0$ & $\times 0$ \\
\hline & rate & 20 & 0 & $\times 0$ & $\times 0$ & $\times 0$ & $\times 0$ & $\times 0$ \\
\hline & $\begin{array}{l}\text { Edit } \\
\text { public } \\
\text { pages }\end{array}$ & 10 & $\times 0$ & $\times 0$ & $\times 0$ & $\times 0$ & $\times 0$ & $\times 0$ \\
\hline & $\begin{array}{l}\text { Setting } \\
\text { Values }\end{array}$ & 0 & $\times 0$ & $\times 0$ & $\times 0$ & $\times 0$ & $\times 0$ & $\times 0$ \\
\hline & \multicolumn{3}{|c|}{ Score needed } & 0 & 100 & 200 & 500 & \\
\hline \multirow{11}{*}{ Reacts: } & comment & 20 & $\times 2$ & $\times 0$ & $\times 0$ & $\times 0$ & $\times 0$ & $\times 0$ \\
\hline & liked & 10 & $\times 3$ & $\times 0$ & $\times 0$ & $\times 0$ & $\times 0$ & $\times 0$ \\
\hline & disliked & -10 & $\times 2$ & $\times 0$ & $\times 0$ & $\times 0$ & $\times 0$ & $\times 0$ \\
\hline & linked & 70 & $\times 2$ & $\times 0$ & $\times 0$ & $\times 0$ & $\times 0$ & $\times 0$ \\
\hline & rated 1 & -15 & $\times 2$ & $\times 0$ & $\times 0$ & $\times 0$ & $\times 0$ & $\times 0$ \\
\hline & rated 2 & -10 & $\times 2$ & $\times 0$ & $\times 0$ & $\times 0$ & $\times 0$ & $\times 0$ \\
\hline & rated 3 & 10 & $\times 2$ & $\times 0$ & $\times 0$ & $\times 0$ & $\times 0$ & $\times 0$ \\
\hline & rated 4 & 30 & $\times 2$ & $\times 0$ & $\times 0$ & $\times 0$ & $\times 0$ & $\times 0$ \\
\hline & rated 5 & 45 & $\times 2$ & $\times 0$ & $\times 0$ & $\times 0$ & $\times 0$ & $\times 0$ \\
\hline & \multicolumn{3}{|c|}{ Score needed } & 0 & 0 & 200 & 500 & \\
\hline & \multicolumn{3}{|c|}{ Total score needed } & 0 & 100 & 400 & 1000 & Invitation \\
\hline
\end{tabular}

Fig. 6 Template "Initiative": thresholds, amount and total score of user activity related to roles and rights. Variables changeable by users are in red. Grey areas show what rights are connected to which role

that does not demand much in terms of critical thinking. In the example in Fig. 6, those actions are therefore not associated with high scores relative to other actions. For instance, to rate something is a more cognitively demanding action than liking or disliking, which motivates its higher minimum value in the suggested template. The rating is also conducted in relation to the history of the collaborative work, thus votes from users with higher status are given a higher reward. In this way, the status of users that have worked for a long time on the topic is emphasised, making it more difficult for new users to change the rules for discussion as well as the overall topic.

The score given can thus have an informative and symbolic function. If attached to roles, it creates a "game" where users level up and receive extended rights by earning score within the system. In the example concerning setting roles and rights in Fig. 6, the "Guest" has the right to read and comment on others' posts and like them but cannot create posts or rate others' posts. To become a "Novice" the user has to obtain a score of 100. As a "Member" the user has rights to do everything except edit public pages. To be allowed to do this, the user has to level up to "Moderator" which demands a sustainable contribution to the topic. To become an "Organiser" with the 


\begin{tabular}{|c|c|c|c|c|c|c|c|c|}
\hline & & \multicolumn{2}{|c|}{ Variables } & \multicolumn{5}{|l|}{ Roles } \\
\hline \multicolumn{2}{|l|}{ Rights } & Score & $\begin{array}{l}\text { Status } \\
\text { impact }\end{array}$ & Guest & Novice & Member & Moderator & Organizer \\
\hline \multirow{9}{*}{ Acts } & $\begin{array}{l}\text { new } \\
\text { post }\end{array}$ & 0 & $\times 0$ & $\times 0$ & $\times 0$ & $\times 0$ & $\times 2$ & $\times 0$ \\
\hline & edit & 0 & $\times 0$ & $\times 0$ & $\times 0$ & $\times 0$ & $\times 0$ & $\times 0$ \\
\hline & comment & 20 & $\times 0$ & $\times 0$ & $\times 3$ & $\times 5$ & $\times 5$ & $\times 0$ \\
\hline & like & 20 & $\times 0$ & $\times 0$ & $\times 1$ & $\times 0$ & $\times 0$ & $\times 0$ \\
\hline & dislike & 0 & $\times 0$ & $\times 0$ & $\times 1$ & $\times 0$ & $\times 0$ & $\times 0$ \\
\hline & rate & 40 & 0 & $\times 0$ & $\times 0$ & $\times 0$ & $\times 0$ & $\times 0$ \\
\hline & $\begin{array}{l}\text { Edit } \\
\text { public } \\
\text { pages }\end{array}$ & 10 & $\times 0$ & $\times 0$ & $\times 0$ & $\times 0$ & $\times 0$ & $\times 0$ \\
\hline & $\begin{array}{l}\text { Setting } \\
\text { Values }\end{array}$ & 0 & $\times 0$ & $\times 0$ & $\times 0$ & $\times 0$ & $\times 0$ & $\times 0$ \\
\hline & \multicolumn{3}{|c|}{ Score needed } & 0 & 100 & 400 & 570 & \\
\hline \multirow{11}{*}{ Reacts } & comment & 40 & $\times 0$ & $\times 0$ & $\times 0$ & $\times 0$ & $\times 0$ & $\times 0$ \\
\hline & liked & 10 & $\times 0$ & $\times 0$ & $\times 0$ & $\times 0$ & $\times 0$ & $\times 0$ \\
\hline & disliked & -10 & $\times 0$ & $\times 0$ & $\times 0$ & $\times 0$ & $\times 0$ & $\times 0$ \\
\hline & linked & 100 & $\times 3$ & $\times 0$ & $\times 0$ & $\times 0$ & $\times 0$ & $\times 0$ \\
\hline & rated 1 & -15 & $\times 3$ & $\times 0$ & $\times 0$ & $\times 0$ & $\times 0$ & $\times 0$ \\
\hline & rated 2 & -10 & $\times 3$ & $\times 0$ & $\times 0$ & $\times 0$ & $\times 0$ & $\times 0$ \\
\hline & rated 3 & 10 & $\times 3$ & $\times 0$ & $\times 0$ & $\times 0$ & $\times 0$ & $\times 0$ \\
\hline & rated 4 & 30 & $\times 3$ & $\times 0$ & $\times 0$ & $\times 0$ & $\times 0$ & $\times 0$ \\
\hline & rated 5 & 45 & $\times 3$ & $\times 0$ & $\times 0$ & $\times 0$ & $\times 0$ & $\times 0$ \\
\hline & \multicolumn{3}{|c|}{ Score needed } & 0 & 0 & 200 & 530 & \\
\hline & \multicolumn{3}{|c|}{ Total score needed } & 0 & 100 & 600 & 1100 & Invitation \\
\hline
\end{tabular}

Fig. 7 Template "Debate": thresholds, amount and total score of user activity related to roles and rights

rights to set the values and thus be able to co-create the rules for the game, the user has to be invited by an organiser.

In the template "Debate" in Fig. 7, the ambition is to reward debate and to give attention to other users. Therefore a new post does not give the active user a score. Instead the user who created the post that is linked to is rewarded. The user can receive score by commenting, liking/disliking, and rating but her activity foremost gives score to others. Users' statuses are emphasised and the score given depends on who reacts. For example, if a user with an actory index of 1.8 (which is $180 \%$ of average) creates a post, the linked post and its user receives $100 \times(1+(3 \times 1.8))=$ 640. But if the active user's actory index is 0.2 the linked post and its user receives $100 \times(1+(3 \times 0.2))=160$.

In order to level up from "Guest" to "Groupie" the user not only has to gain score but also perform certain actions: at least three comments, one like, and one dislike. As a guest, the user is not allowed to create posts or rate other posts and thus can only comment on others' posts and like/dislike. These rules follow the norm for common netiquette in online discussion lists, where new users are supposed to lurk for a while and give attention to the on-going discussion before positioning themselves. To be able to participate in the rating the user has to have submitted at least five comments. 
In this template, it is only the "Boss" who has the right to edit the public part of the groupware, where the objectives of the group are listed and the collective work is abstracted.

\subsection{Preliminary evaluation}

The focus of the study reported here has been to implement a system model and a graphical interface that represent and encourage discursive political practise in explicit ways. The system design is a partial answer to the question of how to account for diversity in groupware. In order to analyse the effect of the tool on group dynamics it should be part of a longitudinal study by, for example, performing repeated experiments with various settings of rules and parameters. Experiments will test the mathematical models empirically and investigate whether various settings would stimulate different kinds of behaviour. The other side of the coin is of course participants' attitudes towards the system-how participants understand the scoring system and the interface. Development of Actory takes place in an iterative manner, and the first usability studies focused primarily on the latter-how participants understand the system. Two studies were performed. The first study had a small group of participants who conducted scenario-based tasks, and the second study lasted for three months for a group with the goal of developing a project.

In the first study, a small representative group of participants was selected among artists, art teachers, and art students at the Royal Institute of Fine Arts in Stockholm. The reason for choosing participants from the art world was that hierarchies are always present in art communities but are also highly implicit and difficult to navigate, especially when participating in collaborative projects. The group was recruited using an open call to participate and consisted of two women and four men between 25 and 50 years old. They were all from different European countries except for one Columbian artist. They shared an interest in communication technologies; half of them claimed that they had very good computer skills, four of them were used to publishing information on the Web, and one had moderated several e-mail lists.

The usability test took 20-30 minutes. During the test, the participants explored the tool using simple scenarios, after which they were interviewed about their impressions of the tool and its possible uses for them. The tool contained fictional profiles and a fictional on-going conversation about organising an art exhibition. The informants were asked to play one of the profiles when acting out the scenarios.

Two types of results stand out: navigational issues and issues relating to our model of status and hierarchy. Our foremost interest lies in the latter, but the former is always an issue in novel prototypes.

The informants had reported difficulties with navigating within Actory; as it was still a prototype it was not yet very user friendly and required a lot of information to be understandable. The tool was perceived as not very intuitive and too textual. The informants also felt that it was difficult to get an overview and to understand the goal of the web site of which the tool was part. This is a problem shared with other blog-like interfaces; new users jump into the middle of the conversation and have to reconstruct the narrative by exploring former posts. One of the main reasons for the confusion was the fictional profiles and conversations: 


\section{"Looks like I have logged into someone else's account."}

The informants' impressions of the tool were clearly marked by their previous experiences of social media. One of the informants described the tool as "a mix between a forum and Facebook". Another informant compared it with a social forum she used that was a place for people in the local art world to publish news about different art events, and she suggested that the tool could have a similar functionality.

Regarding participants' attitudes towards the system's views on group hierarchy etc., they had difficulties understanding the meaning and the functionality of the "status" indicator. One of the participants thought it was related to dating services as she connected the word "status" with civil status. Half of the informants did understand the functionality and the concepts on the status page. However, surprisingly, there was only one informant who actually questioned the basic idea behind the tool:

"Maybe the score method is simplistic. It is too simple for a big [thing]. Social relations are not that, as a simple score. It seems like a game. When you sit down around a table and talk about a project, everything is not a game."

The reason that the lack of questioning surprised us is that we had expected more concerns regarding privacy, control, suppression, etc. to be raised. The lack of problematising the idea with the tool may be explained by various forms of participant bias: the situation, that the informants wanted to show that they were capable of understanding the tool and also that they wanted to please the researchers. The informants were probably also there because of their interest in communication technology. Maybe the reactions would have been much more negative if they were a more representative group of artists and art students at the school. A previous paper showed that social media such as Facebook were seen as something rather negative among art students at the Royal Institute of Art, as a too rational way of handling social relations. Even though most art students use Facebook, they do not like it.

In a follow-up study, twelve persons used the tool during three months, generating around 30 posts and ten times as many comments and likes/dislikes. The tool was used by a group of artists and researchers to develop a common research project and as a complementary to meetings in real life to prepare meetings and to have a place for feedback on sketches.

The two main activities that emerged in the group were memory work (a method for deconstructing ones' own notions concerning a specific subject such as gender, violence etc.) and art project proposals. Memory works is very personal, even though participants express themselves in third person. Due to the personal nature of posts, the atmosphere in comments was good-natured and sympathetic, and this was also reflected in comments regarding project proposals.

The scoring system was set up so that it could not be changed by the users, but it was open for inspection. However, the users were engaged in the discussion and had no interest in the scoring system itself (i.e. how scores were set etc.). Still, the scoring-system as such seemed to encourage participants to contribute to each other's project proposals and recollections. It is frequently the case that participants are more interested in their own proposals than commenting on others'. Actory, in conjunction with the task and context, triggered participants to contribute to the discussion without enforcing them to do so. The emphasis on reactions to each other's posts also 
caused the group as a whole to develop a high sensibility for the roles in the discussion even when they met in real life settings. In other words, the tool and the discussions about the meeting situation triggered by the tool seemed instrumental in fostering a certain behaviour and culture in the group.

Navigation was still problematic in the second study, in part due to the selfregulated structure of the system. Just as in an ordinary blog, the user mostly enters in the middle of conversation and it takes a while to understand the context. But unlike an ordinary blog, Actory consists of many parallel "blogs" that mix into each other. If the user does not constantly follow the flow of information it is easy to get lost. More traditional navigation may therefore be necessary, for example a collaborative menu as in a wiki.

\section{Discussion}

In this article we have challenged the norm in the area of e-participation that all the participants in an interest group are equal. Instead, we have created a tool that assumes the opposite, that everyone is different and that differences create meaning. To find forms for this, we have combined democratic meeting techniques with a scoring system from social media and designed a web-based groupware that functions as a strategic game. Our ambition has been to clarify informal norms and structures by formalising them and make them possible to debate and influence, as when using democratic meeting techniques. The focus has been on the discursive democratic processes that take place in collaborative group discussions online.

To answer our first research question-How should a system based on diversity be conceived? - we have proposed a system that measures users' own activity and the reactions towards these activities. We have assumed, following gender research on on-line communication (Herring 2008; Kampen and Snijkers 2003; Nakamura 2001; Postmes and Spears 2002; Wright 2005), that users will react differently to other participants based on the status position they attribute to the actor, and thus the resulting system visualises these informal structures by counting reactive activity. In this way we avoid a situation where participants judge the status of other participants directly and where status attached to a certain participant is emphasised. Instead, participants' statuses in the system change dynamically and depend both on users' own actions and others' reactions as well as on the changing scores of all users and posts in the system. This is the answer to our second research question: Is it possible to visualise and communicate power structures in the system's design without emphasising or simplifying them? We have created a system that recognises and expects hierarchies without linking them to any designated identity position. This fits well with the idea of status and power as being created in relation to others and not assigned a fixed category.

We also go one step further. Instead of avoiding hierarchy, we emphasise it in order to create a strategic game and to explore hierarchy as a way of enhancing participation. One might ask how the emphasis on the game can create a social culture that promotes collaboration around a common goal. Here the use of game elements in social media has influenced us. In social media, games are sometimes used as a means to inform the user of how to use the platform. Adams and Rollings (2007) define similar motivation in games as economic challenges, when the user is motivated 
by simplistic economic measure of success. Strategy is another important part of the game, understanding the relation of whom you support and vice versa and how the sum of your actions rather than a single move influences your score.

Preliminary studies with our prototype "Actory" have confirmed that such a system may foster certain behaviours, but have also shown difficulties for users in navigating a non-hierarchical system.

It will be interesting to see other game aspects in the design that can be emphasised for different purposes. In our tool, most game aspects have to do with exploration. According to Adams and Rollings (2007) there is always a spatial awareness challenge in exploring a new tool. Creating a map over the terrain makes it easier to navigate, but in order to maintain a challenge one should not make it too easy for the players. There is therefore a point in not revealing all the possibilities and rules in detail but letting the details be revealed when the user has used the system for a while. Locked doors is another game concept that motivates, meaning that knowing there is a higher level is enough, you do not have to declare exactly what the benefits are to level up or how to do it.

Our ambition has been to create a dynamic voting system that reflects the complex systems of meaning in social groups. One of the shortcomings of the system in its current state is, not surprisingly, that it is complex and therefore difficult to explain. To reveal all the rules and give out a lot of information leads to problems with information overload. Just because all the rules are revealed does not mean that users can embrace them all. The usability tests clearly showed the limitations of users' ability to make sense of too much information. Here, the use of gaming challenges like locked doors can create motivation to participate even for those who fail to understand the overall meaning of the "game rules". The rules of communication may instead be presented at a more moderate pace, and understanding can be created through practise rather than by reading a detailed manual.

In this version of the system we haven't taken history into account. Therefore the status of a post does not change as it is becoming old. But if a post becomes old, its relevance usually diminishes if no other users link or like it for a period of time.

The ambition to make the system modifiable by users can also be developed further. As a way of supporting diversity we have devised abilities to express opinions in a variety of fashions. To start with, we have used the most commonly used symbols for discussion and voting online, such as "comment", "like/dislike" and "rate". These different modes of expression are fixed in this version of the system, but a less static and more modifiable system could easily be developed in a future version.

Further empirical research on the platform in use will investigate how users interact with each other and the system, and further incorporation of the algorithms and actory index into e-participation platforms will resolve some of the usability issues in navigating the system.

\section{Conclusion}

We have proposed a groupware that takes diversity and power into account, influenced by democratic meeting techniques and social media practises. Instead of treating technology as a neutral means to an end, we regard it as cultural production and 
use it as a way of expressing and changing norms and social practises. The resulting system is a prototype of a collaborative platform with a game functionality where participants' status is measured and transformed through a dynamic voting process. The participants' status as users depends on their own activity and the reactions of others to these activities: links; likes/dislikes; rating; commenting. Importance is given to users' activity as well as their status position. We assume that users will react based on the actual activity and the status they attribute to the actor. The status position we assume depends on the level of closeness as well as on intersected factors such as gender, class, age, and ethnicity. By measuring participants' activity in relation to each other's actions instead of only their rating of each other, we visualise the presence of structuring factors rather than the actual structure. Participants advance in the system by gathering score and can be given different possibilities to influence the rules based on their score. By looking at the collaborative work in the groupware as a strategic game and using hierarchy as a way to motivate participation, we open up the possibility to communicate complex processes through practical action.

The system will be further developed towards two different uses:

1. A collaborative tool for interest-based networks. This tool can serve as a way to draw attention to individual initiative by visualising how status is created. By using the score as a way to dynamically create roles and provide rights, as in a strategic game, informal roles in the group are visualised and formalised and thus become easier to understand and influence.

2. A research tool for empirically analysing the significance of status, role, transparency and motivation in group processes. The system can be set up differently for different experimental purposes and groups.

The current status of the project is a functional beta, developed in Drupal. We will be testing the tool on larger groups of users during 2013.

Acknowledgements Our thanks to Love Ekenberg, Ernest Rwandalla, Karl David Larsson, the anonymous reviewers, our test participants for their valuable comments, and to Ola Knutsson and Sofia Lindström for assistance in the usability test.

\section{References}

Adams E, Rollings A (2007) Fundamentals of game design. Prentice-Hall, Upper Saddle River

Bondestam F (2002) Könsmedveten pedagogik för universitets-och högskolelärare: en introduktion och bibliografi [Gender-conscious pedagogy for university and college teachers: an introduction and bibliography]. Liber, Stockholm

Dahl RA (1989) Democracy and its critics. Yale University Press, New Haven

Dahlberg L (2007) Rethinking the fragmentation of the cyberpublic: from consensus to contestation. New Media Soc 9:827. doi:10.1177/1461444807081228

Dahlberg L (2011) Re-constructing digital democracy: an outline of four 'positions'. New Media Soc. doi:10.1177/1461444810389569

Dryzek JS (2005) Deliberative democracy in divided societies: alternatives to agonism and analgesia. Polit Theory 33(2):218-242. doi:10.1177/0090591704268372

Dutta-Bergman MJ (2005) New media \& society community satisfaction. New Media Soc 7(1):89-109. doi:10.1177/1461444805049146

Enns CZ, Sinacore AL (2005) Teaching and social justice: integrating multicultural and feminist theories in the classroom. American Psychological Association, Washington 
Fraser N (1985) What's critical about critical theory? The case of Habermas and gender. New Ger Crit 35:97-131

Garcin F, Faltings B, Jurca R (2009) Aggregating reputation feedback. In: Paolucci M (ed) Proceedings of the first international conference on reputation: theory and technology (ICORE 09), Gargonza, Italy, p 233

Hahn C, Fley B, Florian M, Spresny D, Fischer K (2007) Social reputation: a mechanism for flexible self-regulation of multiagent systems. J Artif Soc Soc Simul 10(1):2

Hands J (2005) E-Deliberation and local governance: the role of computer mediated communication in local democratic participation in the United Kingdom. First Monday 10(7). http://www.firstmonday.org/issues/issue10_7/hands/index.html. Accessed 9 February 2013

Hedenstrand S (2008) Konsensus. Anarkism: [tema:] organisering. Anarkistiska studiers förlag

Hemberg G (2002) Frihet, jämlikhet, medborgarskap: handbok i demokratins teori och praktik [Liberty, equality, citizenship: handbook in the theory and practise of democracy]. Ordfront, Stockholm

Herring SC (2000) Gender differences in CMC: findings and implications. CPSR Newslett. 18(1). http://cpsr.org/issues/womenintech/herring/. Accessed 9 February 2013

Herring SC (2008) Gender and power in on-line communication. In: Holmes M, Meyerhoff J (eds) The handbook of language and gender. Blackwell, Oxford. doi:10.1002/9780470756942.ch9d

Howie G, Tauchert A (2001) Gender, teaching, and research in higher education: challenges for the 21st century. Ashgate, Aldershot

Kampen JK, Snijkers K (2003) E-democracy: a critical evaluation of the ultimate e-dream. Soc Sci Comput Rev 21(4):491-496. doi:10.1177/0894439303256095

Klemp NJ, Forcehimes AT (2010) From town-halls to wikis: exploring Wikipedia's implications for deliberative democracy. J Public Delib 6(2). Article 4. http://www.publicdeliberation.net/ jpd/vol6/iss2/art4. Accessed 9 February 2013

Lourenço RP, Costa JP (2010) E-Participation: a discursive approach. In: Ríos Insua D, French S (eds) E-democracy: a group decision and negotiation perspective. Springer, Dordrecht, pp 163-184

Macintosh A, Coleman S, Schneeberger A (2009) eParticipation: the research gaps. Lect Notes Comput Sci 9(1):1-11. doi:10.1007/978-3-642-03781-8_1

Maher FA, Thompson Tetreault MK (2001) The feminist classroom: dynamics of gender, race, and privilege. Rowman \& Littlefield, Lanhamn

Mouffe C (1999) Deliberative democracy or agonistic pluralism. Soc Responsib J 66(3):745-758

Muller G, Vercouter L (2010) LIAR: achieving social control in open and decentralised multi-agent systems. Appl Artif Intell 24(8):723-768. doi:10.1080/08839514.2010.499502

Nakamura L (2001) Head hunting in cyberspace: identity tourism, Asian avatars and racial passing on the web. The women's review of books, vol XVIII

Norris P (2001) Digital divide: civic engagement, information poverty, and the Internet worldwide. Cambridge University Press, Cambridge

Owen H (1997) Open space technology: a user's guide, 2nd edn. Berrett-Koehler, San Francisco

Postmes T, Spears R (2002) Behavior online: does anonymous computer communication reduce gender inequality? Pers Soc Psychol B 28(8):1073-1083. doi:10.1177/01461672022811006

Sabater J, Paolucci M, Conte R (2006) Repage: REPutation and ImAGE among limited autonomous partners. J Artif Soc Soc Simul 9(2):3

Sæbø O, Rose J, Skiftenesflak L (2008) The shape of eParticipation: characterizing an emerging research area. Gov Inform Q 25(3):400-428. doi:10.1016/j.giq.2007.04.007

Witschge T (2002) Online deliberation: possibilities of the internet for deliberative democracy. Public Policy (October): 1-22

Wright MM (2005) Finding a place in cyberspace: black women, technology, and identity. Frontiers 26(1):48-59

Karin Hansson is a graduate student at the Stockholm University pursuing a joint PhD within the Computer- and Systems Science Department and the Royal Institute of Art in Stockholm. She is also an artist and curator and works as a senior lecturer in Media Art at the University of Skövde.

Hansson previously carried out a series of thematic art projects and exhibitions related to information society and changing conditions for democracy. Her research interests in Computer- and Systems Sciences are in the field of e-participation and it includes social theory and gender studies as well as participatory design methods and exploratory artistic methods. 
Petter Karlström $\mathrm{PhD}$, is an associate professor in human-computer interaction at the department of computer and systems sciences, Stockholm University. His research interests concern analysis of language and communication in social media and mobile technology, applied in e-democracy/e-participation, technology enhanced learning, and computer assisted language learning. He has participated in development of Grim - a linguistic tool for second language learning, and has developed computer aids for dysarthric speakers. He has experience in collaborating with municipalities, teachers, journalists and other stakeholders where research results are applicable. Karlström is the coordinator of a bachelor programme in interaction design, and manages an interaction design laboratory room.

Aron Larsson is PhD and associate professor in computer and systems sciences at Stockholm University. $\mathrm{He}$ is also working as a senior lecturer in industrial engineering at Mid Sweden University. His research interests evolve around development and application of methods, tools, and process models for dealing with decision making with many stakeholders, under multiple objectives and uncertainties. He has been developing the DecideIT decision tool and has experience in applying decision theories in public and private sectors, such as urban planning, environmental planning, policy analysis, and investment appraisals.

Harko Verhagen Harko Verhagen received his $\mathrm{PhD}$ degree in computer and systems sciences from Stockholm University (Sweden) in 2000 and is currently an associate professor at the Department of Computer and Systems Sciences at that university. His research has focussed on simulation of organizational behaviour, simulation as a scientific method, the use of sociological theories in multi-agent systems research and more in particular theories on norms and autonomy, combining his background in sociology and computer science.

Other recent research interests include globalization of the ICT industry as an example of reverse globalization, rhetoric and discourse in scientific communication within computer science, and platforms for online discussion promoting micro-democratic processes. 